\title{
The Role of Genre in the Bibliographic Universe
}

\author{
Lei Zhang \\ Information Organization Research Group \\ School of Information Studies \\ University of Wisconsin-Milwaukee \\ zhang68@uwm.edu
}

\author{
Hur-Li Lee \\ Information Organization Research Group \\ School of Information Studies \\ University of Wisconsin-Milwaukee \\ hurli@uwm.edu
}

\begin{abstract}
This paper examines the role of genre in organizing bibliographic information through three sets of modern cataloging rules spanning 171 years: Panizzi's Rules for the Compilation of the Catalogue (91 Rules), Anglo-American Cataloguing Rules Second Edition 2002 Revision (AACR2r), and Resource Description and Access (RDA). Genre-related rules are identified on the basis of their inclusion of the keywords "genre(s)" and "form(s)." Then, the identified rules are analyzed from two aspects: the contexts in which these rules are addressed and four user tasks defined by the Functional Requirements for Bibliographic Records (FRBR)—find, identify, select and obtain. Genre is found absent in 91 Rules and mostly addressed in the note area in AACR2r, while in RDA, genre acts as the primary distinguishing characteristic of work and can be implemented widely as additions to access points, as separate elements, or as both. In conclusion, the paper suggests that the genre concept has yet to be clearly defined and its significance fully articulated in cataloging as well as in the broader discipline of knowledge organization.
\end{abstract}

\section{Keywords}

Genre, Anglo-American cataloging rules, Functional Requirements for Bibliographic Records.

\section{INTRODUCTION}

"Genre" is a French word first used in 1770. Oxford English Dictionary (2012) and Merriam-Webster Dictionary (2012) define genre as kind, sort, style, especially a category of artistic, musical, or literary work characterized by a particular form, content or purpose. Modern genre theories consider genre as far beyond: it can be literary or non-literary, written or spoken, offline or online. Genre has been studied with various perspectives and purposes in linguistic, literary, rhetorical and social disciplines (Schryer, 2009).

This is the space reserved for copyright notices.

Advances in Classification Research, 2012, October 26, 2012, Baltimore, MD, USA.

Copyright notice continues right here.
In library and information studies (LIS), genre has long been recognized as a key consideration in categorizing human communication and, thus, an element for organizing documents in information retrieval systems. The ancient Chinese, for example, recorded the use of genre to organize texts and library collections more than two thousand years ago (Zhang \& Lee, 2012). Since 2010, the Library of Congress has officially separated genre/form terms from its century-old Library of Congress Subject Headings (LCSH), testifying to the increased recognition of genre's importance in information retrieval (Library of Congress, 2010). In a recent article, Andersen (2008) examines the concept of genre and genre-related research and calls for the genre approach to a full range of issues in LIS. He acknowledges three subdomains of LIS that have meaningfully dealt with genre: knowledge organization (KO), Web design, and digital communication.

A review of the $\mathrm{KO}$ literature, however, identified few studies that have investigated the role of genre empirically. Tillett (1991), in her influential work on bibliographic relationships, listed one type of the derivative relationship between two works that results from genre change. At the 1999 ASIS SIG/CR Classification Research Workshop, Davenport (2001) proposed genre analysis as part of the agenda for future classification research. Crowston and Kwasnik (2003) provided several examples to illustrate the treatment of genre in Dewey Decimal Classification and LCSH. Similarly, Maxwell (2007) pointedly used examples to explain genre/form headings in LCSH and how they relate to the bibliographic model of Functional Requirements for Bibliographic Records (FRBR). None of these examined genre in depth or systematically despite its ubiquity. In fact, Crowston and Kwasnik (2003) correctly stated that genre has been taken for granted in $\mathrm{KO}$ systems.

Nevertheless, changes are on the horizon. A significant development in the bibliographic universe has seen the increasing importance of the FRBR model as the Englishspeaking countries are preparing to implement the new cataloging code Resource Description and Access (RDA)a code built on the FRBR model. FRBR's focus on the functions of bibliographic data to meet user requirements is closely aligned with the genre concept in emphasizing the function and purpose of documents in the contexts of their creation and use. This latest model, in our view, provides an 
Zhang, L., \& Lee, H. (2013). The Role of Genre in the Bibliographic Universe. Advances In Classification Research Online, 23(1), pp. 38-45. doi:10.7152/acro.v23i1.14236

excellent opportunity for investigating genre's role in bibliographic systems because of two particular features in FRBR: (1) its systematic organization of data about information resources by a four-level structure of workexpression-manifestation-item; and (2) its articulated mapping of bibliographic data to four user tasks:

- Find: to find [a single or a set of] entities that correspond to the user's stated search criteria

- Identify: to confirm that the entity corresponds to what sought by the user; or, to distinguish between two or more entities with similar characteristics

- Select: to select an entity that is appropriate to the user's needs

- Obtain: to acquire through purchase, loan, online access

This paper reports part of our ongoing work, which seeks to examine the role of genre in organizing bibliographic information with an eye to the FRBR user tasks. The first step in our research is to trace the treatment of genre in modern Anglo-American cataloging rules, including RDA, which shall then lead to future study to enhance RDA and other bibliographic standards in their dealing with genre. The questions we find interesting are: how has genre been defined conceptually in resource description and access, how have genre instances been categorized, and more importantly, how has the function of genre been utilized in the bibliographic universe? Here, the concept of genre we adopt is the most common one-the relatively stable and expectable form and content for communication, though definition of genre is well worth a study of its own.

\section{METHODOLOGY}

To address our research questions, we examined three sets of cataloging rules: Rules for the Compilation of the Catalogue (1841), Anglo-American Cataloguing Rules Second Edition 2002 Revision (2005; commonly known as AACR2r), and Resource Description and Access (RDA) (2012). The first one we used was an electronic copy accessible in a digital library, while the latter two were the online version in the RDA Toolkit (http://access.rdatoolkit. org/).

Rules for the Compilation of the Catalogue (91 Rules) by Anthony Panizzi, which intended to guide in the compilation of the printed catalogs of British Museum, has been known as the progenitor of modern cataloging. AACR2 $r$ is the current standard for constructing catalog records in English language libraries. Published jointly by the American Library Association, the Canadian Library Association, and the Chartered Institute of Library and Information Professionals in the UK, AACR was developed from its first emergence in 1967, re-editioned in 1978, and significantly revised in 1988 and 2002. As successor to AACR2r, RDA was released in 2010, and aims to support all types of content and media. The Library of Congress and several other national libraries have planned to implement RDA in 2013. Therefore an examination of these three documents may enable us to see the role of genre and its changes throughout the development of cataloging codes in the Anglo-American tradition spanning 171 years.

We first conducted a search with the keywords "genre(s)" and "form(s)", both singular and plural, in the three sets of cataloging rules since the term "form", in a broader sense, has been used in place of "genre" most often in these documents. For example, the only occurrence of "genre" in AACR2r (rule 25.27A1) states, "the name of a type of composition ... is considered to be the name of a form, the name of a genre ..."; RDA (rule 6.3.1.1) also gives a definition as "form of work is a class or genre to which a work belongs." "Genre" and "form" are also often used together such as "genre/form headings" or "genre/form terms" in a range of documents, including the thesaurus Library of Congress Genre/Form Terms for Library and Archival Materials.

A total of 700 results containing the term "genre(s)" or "form(s)" were returned from the three documents: 6 from Panizzi's 91 Rules, 229 from AACR2r, and 465 from RDA. From these results, only those rules that do address the concept of genre were selected for analysis, while the rules that just linguistically or literally containing the terms were removed. We also excluded those occurring in the appendices, glossary and index. Panizzi's 91 Rules was temporarily set aside after the procedure for the purpose of this paper, but will remain as part of our larger study.

To analyze the rules, we need to understand how contents are organized in AACR2r and RDA respectively. AACR2r consists of two parts. Part I deals with the descriptive part of a catalog record, in which the first chapter provides the general rules, and the subsequent chapters set rules for specific formats (e.g., Books, Pamphlets, and Printed Sheets; Cartographic Materials; Manuscripts; Music; Sound Recordings; Motion Pictures and Videorecordings; Graphic Materials; Electronic Resources; Three-Dimensional Artefacts and Realia; Microforms; and Continuing Resources). Each chapter is further divided into eight areas prescribed by the International Standard for Bibliographic Control (ISBD Review Group, 2011), i.e., title and statement of responsibility, edition, material specific details, publication information, physical description, series, note, and standard number and terms of availability. Part II deals with the choice as well as formatting of name and title access points (i.e., index terms). Name access points are those of personal names, geographic places, and corporate bodies.

In RDA, Part I discusses the bibliographic entities and their attributes in three groups: Group 1 (Work, Expression, Manifestation, Item), Group 2 (Persons, Families, Corporate bodies), and Group 3 (Concepts, Objects, Events, Places). Part II discusses their relationships: Group 1, Group 2, or Group 3 entities related to Group 1 entities; and 
Zhang, L., \& Lee, H. (2013). The Role of Genre in the Bibliographic Universe. Advances In Classification Research Online, 23(1), pp. 38-45. doi:10.7152/acro.v23i1.14236

relationships among entities within each of Group 1, Group 2 , or Group 3. These three groups of entities originate from the conceptual model established in FRBR, which defines the entities in terms of their attributes and relationships to other entities.

Next, we will proceed to analyze the selected genre-related rules from two aspects: the contexts in which the rules are addressed and the functional tasks these rules aim for.

\section{GENRE IN MODERN CATALOGING STANDARDS}

There are 13 genre-related rules identified from AACR2r and 15 rules from RDA, among which 1 in AACR2r and 7 in RDA contained the keyword "genre(s)" and the rest contained "form(s)." The analysis of these rules is reported and discussed in the following two sections, by context and by task.

\section{Contexts}

First, we examined the contexts in which these rules are addressed; that is, whether the rules are general guidelines, a specific treatment of genre, or a specific treatment of another element with genre as a condition.

\section{AACR2r}

In AACR2r, the contents are organized by format and further by area. Table 1 presents the results of the analysis as genre-related rules in AACR2r categorized by context. From this table we may see the distribution in regard to the addressing of "genre(s)" or "form(s)" in AACR2r.

\begin{tabular}{|c|c|c|c|}
\hline AACR2r & Format & Area & Treatment \\
\hline $1.7 \mathrm{~B} 1$ & \multirow[t]{5}{*}{ General } & Note & Specific \\
\hline $21.10 \mathrm{~A}$ & & & Condition \\
\hline $25.9 A$ & & & \\
\hline $25.10 \mathrm{~A}$ & & & \multirow[t]{10}{*}{ Specific } \\
\hline $25.27 \mathrm{D} 1$ & & & \\
\hline $2.7 \mathrm{~B} 1$ & $\begin{array}{l}\text { Books, Pamphlets, } \\
\text { and Printed Sheets }\end{array}$ & Note & \\
\hline 4.7B1 & Manuscripts & & \\
\hline $5.7 \mathrm{~B} 1$ & \multirow[t]{2}{*}{ Music } & & \\
\hline 5.7B18 & & & \\
\hline $6.7 \mathrm{~B} 1$ & Sound Recordings & & \\
\hline 7.7B1 & $\begin{array}{l}\text { Motion Pictures and } \\
\text { Videorecordings }\end{array}$ & & \\
\hline $8.7 \mathrm{~B} 1$ & Graphic Materials & & \\
\hline $11.7 \mathrm{~B} 1$ & Microforms & & \\
\hline
\end{tabular}

Table 1. Genre-related Rules in AACR2r by Context

Out of the selected 13 rules in AACR2r, 9 come from the note area across chapters in Part I, while the rest are from Chapter 21 Choice of Access Points and Chapter 25 Uniform Titles in Part II. Below, the searched keywords "genre(s)" and "form(s)" in quoted rules are underlined.

The general rules about notes are stated in the first chapter 1.7B. Notes as below,

Give notes in the order in which they are listed here. However, give a particular note first when it has been decided that note is of primary importance.

From among the list the first one is relevant to genre, as stated in 1.7B1. Nature, Scope, or Artistic Form with the following examples,

\section{Comedy in two acts}

Documentary

Genre is widely addressed in the note area in the subsequent chapters for specific formats as follows, instructed as to make notes on these matters unless they are apparent from the rest of the description.

2.7B1. Nature, scope, or artistic form (Books, Pamphlets, and Printed Sheets)

4.7B1. Nature, scope, or form (Manuscripts)

5.7B1. Form of composition and medium of performance; 5.7B18. Contents (Music)

6.7B1. Nature or artistic form and medium of performance (Sound Recordings)

7.7B1. Nature or form (Motion Pictures and Videorecordings)

8.7B1. Nature or artistic form (Graphic Materials)

11.7B1. Nature, scope, or artistic or other form of an item (Microforms)

The examples provided show that genres vary with different formats. For example, we observe genre diversity in Books, Pamphlets, and Printed Sheets format (e.g., collection of essays on economic subjects, Arabic reader, play in 3 acts, scenario of film), Music format (e.g., carol, opera in two acts), and Motion Pictures and Videorecordings format (e.g., documentary, TV play).

The other genre-related rules are from Part II of AACR2r, among which the rules in Chapter 25 Uniform Titles 25.10A and $25.27 \mathrm{Al}$ are a specific treatment of genre. $25.10 \mathrm{~A}$ deals with works in a single form as follows,

Use one of the following collective titles for an item (other than music, see 25.34C) that consists of, or purports to be, the complete works of a person in one particular form.

Correspondence

Essays

Novels

Plays

Poems

Prose works

Short stories

Speeches 
Zhang, L., \& Lee, H. (2013). The Role of Genre in the Bibliographic Universe. Advances In Classification Research Online, 23(1), pp. 38-45. doi:10.7152/acro.v23i1.14236

If none of these is appropriate, use an appropriate specific collective title (e.g., Posters, Fragments).

If the item consists of three or more but not all of the works of one person in a particular form, or of extracts, etc., from the works of one person in a particular form, add Selections to the collective title.

25.27Al indicates that we need to follow other instructions if the title includes the name of a type of composition, whose interpretation is given in a note as below,

The name of a type of composition, as distinguished from a distinctive title, is considered to be the name of a form, the name of a genre, or a generic term used frequently by different composers (e.g., capriccio, concerto, intermezzo, Magnificat, mass, movement, muziek, nocturne, requiem, Stuck, symphony, suite, Te Deum, trio sonata). Other titles (including those that consist of such terms plus an additional word or words, e.g., chamber concerto, Konzertstiick, little suite) are considered to be distinctive.

Thus leading to a relevant rule $25.27 D 1$ that actually instructs on how to deal with genre,

If all of a composer's works with titles (selected according to $25.27 \mathrm{~A}-25.27 \mathrm{C}$ ) that include the name of a type of composition are also cited as a numbered sequence of compositions of that type, use the name of the type of composition as basis for the uniform title (see 25.29).

The other two rules $21.10 \mathrm{~A}$ and $25.9 \mathrm{~A}$, though relevant to genre, discuss adaptations of texts and selections as collective titles correspondingly, with genre as a condition.

21.10A. Enter a paraphrase, rewriting, adaptation for children, or version in a different literary form (e.g., novelization, dramatization) under the heading for the adapter. If the name of the adapter is unknown, enter under title. Make a name-title added entry for the original work. In case of doubt about whether a work is an adaptation, enter under the heading for the original work.

\section{$R D A$}

Instead of dividing bibliographic elements into format and area, RDA organizes its contents based on FRBR's three groups of entities and their attributes. As shown in Table 2, and aside from two rules in the Introduction chapter and one rule in Chapter 8 relating Group 2 entities to Group 1 entities, most genre-related rules are in Chapters 5 and 6 of
Section 2 Recording Attributes of Work \& Expression, where Work is defined as a distinct intellectual or artistic creation, while Expression as the intellectual or artistic realization of a work.

\begin{tabular}{|c|c|c|c|}
\hline RDA & Entity & Attribute & Treatment \\
\hline 0.4 .2 .1 & General & \multirow[t]{5}{*}{ Form } & \multirow[t]{2}{*}{ General } \\
\hline 0.6 .3 & \multirow[t]{13}{*}{ Works } & & \\
\hline 5.2 & & & \multirow[t]{4}{*}{ Specific } \\
\hline 5.3 & & & \\
\hline 5.5 & & & \\
\hline 6.2 .2 .10 .2 & & \multirow[t]{2}{*}{ Title } & \\
\hline 6.2.2.10.3 & & & Condition \\
\hline 6.3 & & \multirow[t]{7}{*}{ Form } & \multirow[t]{4}{*}{ Specific } \\
\hline 6.3 .1 .1 & & & \\
\hline 6.3.1.2 & & & \\
\hline 6.3.1.3 & & & \\
\hline 6.6 .1 .1 & & & \multirow[t]{2}{*}{ Condition } \\
\hline 6.21 .1 .1 & & & \\
\hline 6.27 .1 .9 & & & Specific \\
\hline 8.8 .1 .1 & $\begin{array}{l}\text { Persons, } \\
\text { Families, } \\
\text { Corporate } \\
\text { Bodies }\end{array}$ & Name & Condition \\
\hline
\end{tabular}

Table 2. Genre-related Rules in RDA by Context

"Form" is first addressed in the objectives of RDA, as in 0.4.2.1 Responsiveness to User Needs,

The data should enable the user to:

$\cdots$

select a resource appropriate to the user's requirements with respect to form, intended audience, language, etc.

"Form" is further addressed as a core element of work, as in 0.6.3 Section 2: Recording Attributes of Work and Expression,

If the preferred title for a work is the same as or similar to a title for a different work, or to a name for a person, family, or corporate body, record as many of the additional identifying elements listed below as necessary to differentiate them. Record the elements either as additions to the access point representing the work, as separate elements, or as both.

Form of work

Date of work

Place of origin of the work

Other distinguishing characteristic of the work $\cdots$

"Form" is then elaborated in Chapter 5 General Guidelines 
on Recording Attributes of Works and Expressions and Chapter 6 Identifying Works and Expressions. The above idea in 0.4.2.1 is specified in Section 5.2 Functional Objectives and Principles,

e) select a work or expression that is appropriate to the user's requirements with respect to form, intended audience, language, etc.

The idea in 0.6.3 is repeated in Section 5.3 Core Elements, which states "form of work", together with "date of work" and "place of origin of the work", as a principal identifying element of a work. Furthermore, as noted by 5.5 Authorized Access Points Representing Works and Expressions,

If two or more works are represented by the same or similar access points, add to the access point representing the work an element or elements such as form of work, date, place of origin, or other distinguishing term. For specific instructions on additions to access points representing works, see 6.27.1.9.

Section 6.3 Form of Work gives specific instructions on recording form of work,

\subsection{Form of Work \\ CORE ELEMENT}

Form of work is a core element when needed to differentiate a work from another work with the same title or from the name of a person, family, or corporate body.

6.3.1 Basic Instructions on Recording Form of Work

\subsubsection{Scope}

Form of work is a class or genre to which a work belongs.

\subsubsection{Sources of Information}

Take information on form of work from any source.

\subsubsection{Recording Form of Work}

Record the form of the work.

The other two rules in Chapter 6 with treatment of genre are 6.2.2.10.2 and 6.27.1.9. The former, 6.2.2.10.2 Complete Works in a Single Form, corresponds to $25.10 \mathrm{~A}$ in AACR2r,

Record one of the following conventional collective titles as the preferred title for a compilation of works (other than music, see 6.14.2.8) that consists of, or purports to be, the complete works of a person, family, or corporate body, in one particular form.

6.27.1.9 Additions to Access Points Representing Works extends rule 5.5 as below,

If the access point constructed by applying the instructions given under 6.27.1.2-6.27.1.8 is the same as or similar to an access point representing a different work, or to an access point representing a person, family, corporate body, or place, add one or more of the following, as appropriate:

a) a term indicating the form of work (see 6.3)

b) the date of the work (see 6.4)

c) the place of origin of the work (see 6.5) and/or

d) a term indicating another distinguishing characteristic of the work (see 6.6).

The other four rules are just treatment of genre as a condition. For example, 6.2.2.10.3 Other Compilations of Two or More Works discusses other compilations of two or more works,

For a compilation consisting of:

a) two or more but not all the works of one person, family, or corporate body, in a particular form

or

b) two or more but not all the works of one person, family, or corporate body, in various forms

record the preferred title for each of the works in the compilation applying the basic instructions on recording titles of works given under 6.2.1.

Rules 6.6.1.1 and 6.21.1.1 discuss other distinguishing characteristics of the general work and legal works respectively other than form, date, and place of origin of the work; and 8.8.1.1 discusses form of work associated with the name designated as the preferred name for a person, family, or corporate body.

\section{Discussion}

Of all 700 results, the term "genre" makes 8 appearances in AACR2r and RDA; instead, "form" is used more frequently, however, in a variety of meanings. "Form" is only defined in 6.3.1.1 of RDA, corresponding to its definition in FRBR (2009) as an attribute of a work, "the 
Zhang, L., \& Lee, H. (2013). The Role of Genre in the Bibliographic Universe. Advances In Classification Research Online, 23(1), pp. 38-45.

class to which the work belongs (e.g., novel, play, poem, essay, biography, symphony, concerto, sonata, map, drawing, painting, photograph, etc.)" (p. 34), though not all in the list are the equivalent of genre. Most occurrences of "form" in the rules stand for meanings like what is defined as an attribute of expression in FRBR, "the means by which the work is realized (e.g., through alphanumeric notation, musical notation, spoken word, musical sound, cartographic image, photographic image, sculpture, dance, mime, etc.)" (p. 36), or like what is defined as an attribute of manifestation in FRBR, "the specific class of material to which the physical carrier of the manifestation belongs" ( $p$. 43). When we looked at specific rules in Chapter 6, it became clear that "form" as the near-synonym of genre is only associated with "work", not "expression" or "manifestation", where "form" is closer in nature to the form as in the triplet of genre comprising form, content and purpose. Additionally, the term "type" or "class" is occasionally used as a replacement in the rules. It shows that the concept of genre has not been clearly defined and the use of terminology for genre is inconsistent throughout these cataloging rules.

Since genre has traditionally been associated with artistic, musical, and literary compositions, it is not surprising that there are more genre-related rules about music than other formats, even without the inclusion of "type(s) of composition" predominantly occurring in Chapter 25 of AACR2r and Chapter 6 of RDA, and that the genre-related rules are more likely to deal with the literary genres in both standards, as in the rules about adaptations of texts and collective titles.

Other than the above commonalities, differences exist between RDA and AACR2r in regard to the genre concept. In AACR2r, the genre concept is mostly addressed in one of the eight descriptive areas - the note area, while in RDA it mainly appears at the most abstract and basic levelWork. "Form of work", a referent that encompasses genre, has been addressed independently as a core element, first in the Introduction and then in the subsequent chapters. All of these show an increased recognition of the significance of genre in cataloging rules from AACR2r to RDA.

\section{Tasks}

Since FRBR's user tasks (i.e., find, identify, select and obtain) are a guiding principle behind RDA, we also examined the genre-related rules through tasks as another lens.

\section{AACR2r and RDA}

Table 3 presents the results as genre-related rules categorized by FRBR task, for both AACR2r and RDA.

The categories to which these rules belong were first decided by the general guidelines in the first chapter of each section in RDA, which outlines the purposes of the elements described in the following chapters.

\begin{tabular}{|l|l|l|}
\hline Tasks & AACR2r & \multicolumn{1}{|c|}{ RDA } \\
\hline Find & $25.10 \mathrm{~A}$ & 5.5 \\
& $25.27 \mathrm{D} 1$ & 6.2 .2 .10 .2 \\
& & 6.27 .1 .9 \\
\hline Identify & $1.7 \mathrm{~B} 1$ & 0.6 .3 \\
& $2.7 \mathrm{~B} 1$ & 5.3 \\
& $4.7 \mathrm{~B} 1$ & 5.5 \\
& $5.7 \mathrm{~B} 1$ & 6.2 .2 .10 .2 \\
& $5.7 \mathrm{~B} 18$ & 6.2 .2 .10 .3 \\
& $6.7 \mathrm{~B} 1$ & 6.3 \\
& $7.7 \mathrm{~B} 1$ & 6.3 .1 .1 \\
& $8.7 \mathrm{~B} 1$ & 6.3 .1 .2 \\
& $11.7 \mathrm{~B} 1$ & 6.3 .1 .3 \\
& $21.10 \mathrm{~A}$ & 6.6 .1 .1 \\
& $25.9 \mathrm{~A}$ & 6.21 .1 .1 \\
& $25.10 \mathrm{~A}$ & 6.27 .1 .9 \\
& $25.27 \mathrm{D} 1$ & 8.8 .1 .1 \\
\hline Select & $1.7 \mathrm{~B} 1$ & 0.4 .2 .1 \\
& $2.7 \mathrm{~B} 1$ & 0.6 .3 \\
& $4.7 \mathrm{~B} 1$ & 5.2 \\
& $5.7 \mathrm{~B} 1$ & 5.3 \\
& $5.7 \mathrm{~B} 18$ & 6.2 .2 .10 .2 \\
& $6.7 \mathrm{~B} 1$ & 6.3 \\
& $7.7 \mathrm{~B} 1$ & 6.3 .1 .1 \\
& $8.7 \mathrm{~B} 1$ & 6.3 .1 .2 \\
& $11.7 \mathrm{~B} 1$ & 6.3 .1 .3 \\
& & 6.27 .1 .9 \\
\hline
\end{tabular}

Table 3. Genre-related Rules Categorized by Task

The RDA chapters focus on elements supporting specific FRBR user tasks. For example,

\begin{tabular}{|c|c|}
\hline Chapter 1 & General guidelines \\
\hline Chapter 2 & $\begin{array}{l}\text { Identifying manifestations and } \\
\text { items (FRBR task: identify) }\end{array}$ \\
\hline Chapter 3 & $\begin{array}{l}\text { Describing carriers (FRBR task: } \\
\text { select) }\end{array}$ \\
\hline Chapter 4 & $\begin{array}{l}\text { Providing acquisition and access } \\
\text { information (FRBR task: obtain) }\end{array}$ \\
\hline \multicolumn{2}{|l|}{$\cdots$} \\
\hline Chapter 30 & $\begin{array}{l}\text { Related persons (FRBR task: } \\
\text { find) }\end{array}$ \\
\hline Chapter 31 & $\begin{array}{l}\text { Related families (FRBR task: } \\
\text { find) }\end{array}$ \\
\hline Chapter 32 & $\begin{array}{l}\text { Related corporate bodies (FRBR } \\
\text { task: find) }\end{array}$ \\
\hline
\end{tabular}

Our judgments were also based on the nature of these rules. For example, access points always serve the finding function, therefore AACR2r rules 25.10A and 25.27D1 are in the category of "Find", while rules in the note area are mostly for "Identify" and probably for "Select". According to what is stated in Chapter 5 in RDA, rules in Chapter 6 serve the function of identification,

This chapter sets out the functional objectives and principles underlying the guidelines and 
Zhang, L., \& Lee, H. (2013). The Role of Genre in the Bibliographic Universe. Advances In Classification Research Online, 23(1), pp. 38-45. doi:10.7152/acro.v23i1.14236

instructions in chapters 6-7 on recording data identifying and describing works and expressions, and specifies core elements for the identification and description of those entities.

However, we considered that identify and select would be somewhat overlapped with different emphasis, so some rules belonging to "Identify" category also fell into the category of "Select", such as 0.6.3, 5.3, 6.2.2.10.2, 6.3, 6.27.1.9, etc. On the other hand, rules like 6.2.2.10.3, 6.6.1.1, 6.21.1.1 and 8.8.1.1 actually are the treatment of genre as a condition, so they only have the function as "Identify". RDA rules 5.5, 6.2.2.10.2, and 6.27.1.9 involve genre in access points, thus serve the find task. In all, some genre-related rules have multiple functions supporting three FRBR tasks "Find", "Identify" and "Select", such as 6.27.1.9, whereas some rules only have one function, such as 6.6.1.1.

\section{Discussion}

What is common between AACR2r and RDA in terms of user tasks is that both address genre when differentiation between resources is deemed necessary and both consider genre as the primary identifying element as compared to others. For example, AACR2r lists nature, scope, or artistic form as the first among a range of items for inclusion in the note area, while RDA emphasizes form as one of the three key characteristics - the other two being date and place of origin - to distinguish one work from another. Table 3 shows that among the four FRBR user tasks, identify and select are the two most common functions for these genrerelated rules. FRBR (2009) itself assigns high value to the attribute "form of work" for its support of the select task (p. 84). At the same time, FRBR assigns only moderate value to "form of work" for its support of the identify and find tasks.

Table 3 also tells us that fewer genre-related rules in both AACR2 $r$ and RDA associate genre with the finding function. These rules instruct on the inclusion of genre terms as uniform titles and aim to facilitate the find task in two ways. On the one hand, a genre term may be used as a uniform title to collocate works in the same genre by one person or corporate body (e,g., all poems by Maya Angelou). On the other hand, when such a genre uniform title is used in an access point to reference a related work, it helps the user find that related work.

Regardless of whether these genre-related rules are about encoding genre information itself or about the use of genre information to influence the encoding of other metadata elements, it shows that the functions of genre certainly cannot be ignored. It is anticipated that a full exploitation of genre functions will support effective information seeking.

\section{CONCLUSION}

This paper analyzed the role of genre in the bibliographic universe through an examination of three sets of modern Anglo-American cataloging rules dating from 1841 to the present. From the absence of the searched keywords in Panizzi's 91 Rules to fragmented statements concerning genre in AACR2 $r$ to pronounced application of genre as a core element in RDA, it showed that the role of genre has been gradually recognized and enhanced in cataloging. The leveled distinction of FRBR Group 1 entities enabled us to clearly see genre as an element closely associated with the entity of work in the bibliographic universe, and FRBR's emphasis on the functions of information systems and user tasks enabled us to understand genre as one of the primary characteristics that assist the user in distinguishing one work from another. Finally, as demonstrated in RDA, genre as an attribute of work can be implemented widely as additions to access points, as separate descriptive elements, or as both. As a whole, genre exhibits an increasingly important role in RDA, compared with its predecessors, in serving the functions of identifying, selecting, and finding.

This is the first study approaching FRBR through the concept of genre. No doubt, the use of the keywords "genre(s)" and "form(s)" to identify relevant rules in the selected cataloging standards might have left out other rules that are relevant but lacking the specific keywords. Our next step is to conduct a thorough scrutiny of the rules manually to discover additional rules in major cataloging standards, including what were examined in this paper.

The current study has also exposed the problem of terminology in its ambiguous use of "form" vs. "genre." Throughout all three sets of rules examined for the study, neither form nor genre is defined. Sometimes, the only way to know for certain that a rule is indeed relevant is by perusing the examples given under that particular rule. Information professionals specializing in subject vocabularies have likewise encountered such a problem and made some attempt to distinguish the two concepts (Library of Congress, 2010). When further considering the commonly accepted concept of genre in three intersecting dimensions (i.e., content, form, and purpose), it becomes abundantly clear that we must not continue the use of form/genre without clarification. An effective definition of genre for knowledge organization, however, will have to depend on a thorough understanding of genre's contentform-purpose, all of which are part of our long-term research agenda.

The rules examined above are those for resource description and name/title access points due to the fact that both AACR2r and the current version of RDA only cover those aspects in cataloging. In practice, genre has also had a persistent presence in the subject area. Various information professions, including cataloging, have since the 1980s created subject thesauri devoted entirely to genre and form terms. As RDA develops its section on subject analysis, we can anticipate that genre's role in knowledge organization will continue to be further articulated and expanded. 
Zhang, L., \& Lee, H. (2013). The Role of Genre in the Bibliographic Universe. Advances In Classification Research Online, 23(1), pp. 38-45. doi:10.7152/acro.v23i1.14236

\section{REFERENCES}

Andersen, J. (2008). The concept of genre in information studies. Annual Review of Information Science and Technology, 42, 339-367.

Anglo-American Cataloging Rules, Second Edition 2002 Revision. (2005). Prepared by the Joint Steering Committee for Revision of AACR. American Library Association. Retrieved July 17, 2012 from: http://access.rdatoolkit.org/

Crowston, K., \& Kwasnik, B.H. (2003). Can documentgenre metadata improve information access to large digital collections? Library Trends, 52, 345-361.

Davenport, E. (2001). Implicit orders: Documentary genres and organizational practice. In H. Albrechtsen \& J.-E. Mai (Eds.), Advances in Classification Research: Proceedings of the 10th ASIS SIG/CR Classification Research Workshop (pp. 39-54). Medford: Information Today.

IFLA Study Group on the Functional Requirements for Bibliographic Records. (2009). Functional requirements for bibliographic records: final report, as amended and corrected through February 2009. Retrieved July 17, 2012 from: http://www.ifla.org/VII/s13/frbr/.

ISBD Review Group. (2011). ISBD: International Standard Bibliographic Description. Consolidated ed. Berlin: De Gruyter Saur.

Library of Congress. (2010). Library of Congress to formally separate LC genre/form thesaurus from LCSH. Retrieved August 23, 2012 from: http://www.loc.gov/catdir/cpso/genreformthesaurus.html

Maxwell, R.L. (2007). Genre/form: Introduction and its relationship to FRBR. American Library Association Conference. Retrieved August 1, 2012 from: http://www.ala.org/alcts/files/events/pastala/annual/07/m axwell_gfpaper.doc

Merriam-Webster Dictionary. (2012). Retrieved October 21, 2012 from: http://www.merriam-webster.com/

Oxford English Dictionary. (2012). Retrieved October 21, 2012 from: http://www.oed.com.ezproxy.lib.uwm.edu/

Panizzi, A. (1841). Rules for the compilation of the catalogue. In Catalogue of Printed Books in the British Museum Vol. I (pp. v-ix). London: J.B. Nichols and Son.

Resource Description and Access. (2012). Prepared by the Joint Steering Committee for Development of RDA. American Library Association. Retrieved July 17, 2012 from: http://access.rdatoolkit.org/

Schryer, C. F. (2009). Genre theory and research. In M. Bates \& M.N. Maack (Eds.), Encyclopedia of Library and Information Sciences (3rd ed., pp. 1934-1942). New York: Taylor and Francis.

Tillett, B. (1991). A taxonomy of bibliographic relationships. Library Resources \& Technical Services, $35,150-158$

Tillett, B. (2007). FRBR and RDA: Resource description and access. In A.G. Taylor (Ed.), Understanding FRBR: What it is and how it will affect our retrieval tools (pp. 87-95). Westport: Libraries Unlimited.

Zhang, L., \& Lee, H.-L. (2012). Rethinking genre in knowledge organization through a functional unit taxonomy. In R.P. Smiraglia \& H.-L. Lee (Eds.), Cultural Frames of Knowledge (pp. 135-149). Würzburg: ErgonVerlag. 